\title{
A criatividade do professor: a relação entre o sentido subjetivo da criatividade e a pedagogia de projetos
}

\author{
A criatividade do professor: sentido e ação
}

\author{
Renata Fernandes Mourão \\ Albertina Mitjáns Martínez
}

\begin{abstract}
Resumo
Buscou-se compreender a relação entre o sentido subjetivo da criatividade do professor e sua prática pedagógica com projetos. Partiu-se da teoria históricocultural da subjetividade desenvolvida por González Rey (1997, 1999, 200I, 2002b, 2004). O método adotado foi o estudo de caso com dois professores que trabalham com projetos de estratégia relativos ao ensino-aprendizagem em uma mesma escola. Vários instrumentos foram utilizados: a técnica de completamento de frases, redações, observação direta, análise documental e, principalmente, a entrevista como processo. Como conclusão principal, percebeu-se que se trata de uma relação recursiva. Além disso, a pesquisa demonstrou que os sentidos subjetivos de importantes aspectos contextuais como o espaço em sala de aula - são mediadores da relação colocada sob foco. Por fim, notou-se que conflitos e contradições vividos na prática com projetos configuram-se como uma situação potencial de desenvolvimento em relação ao sentido subjetivo da criatividade e à própria prática docente.

Palavras-chave: Criatividade do professor; Subjetividade; Pedagogia de projetos.
\end{abstract}

\section{Teacher's creativity: The relation between the subjective sense of creativity and the project practice}

\begin{abstract}
We tried to understand the relation between the teacher's subjective sense of creativity and the project teaching practice. The historical cultural view of subjectivity provides the theoretical background through the ideas developed by González Rey. We adopted the method of case study, with two teachers that use projects as a teaching and apprenticeship strategy in the same school. Many instruments were used like the technique of completing sentences, text writing, direct observation, document analysis and - the main one - the interview as a process. As the most important conclusion, a recursive relation was found. The research also shows that the subjective sense of the contextual aspects - like the subjective sense of the classroom is mediating the studied relation. Finally, we noted that conflicts and contradictions experienced in the project practice represent a potential situation for the development of the teacher's subjective sense of creativity and the teaching practice itself.
\end{abstract}

Key words: Teacher's creativity; Subjective; Project teaching practice.

\section{Creatividad del profesor: la relación entre sentido subjetivo de la creatividad y pedagogía de proyectos}

\section{Resumen}

Buscamos entender la relación entre el sentido subjetivo de la creatividad del profesor y su práctica pedagógica con proyectos. Se partió de la teoría histórico-cultural de la subjetividad, desarrollada por González Rey (1997, 1999, 200I, 2002b, 2004). El método adoptado fue el estudio de caso; con dos profesores que trabajan con proyectos como estrategia de enseñanza-aprendizaje en la misma escuela. Se utilizaron varios instrumentos: la técnica de completar frases, redacciones, observación directa, análisis documental y, principalmente, la entrevista como proceso. Como conclusión principal, se percibió que se trata de una relación recursiva. Además de eso, la investigación demostró que los sentidos subjetivos de importantes aspectos contextuales - como del espacio de sala de aula - son mediadores de la relación colocada sobre foco. Finalmente; se ha notado que conflictos y contradicciones vividos en la práctica con proyectos se configuran como una situación potencial de desarrollo, en relación al sentido subjetivo de la creatividad y a la propia práctica docente.

Palabras-clave: Creatividad del profesor; Subjetividad; Pedagogía de proyectos. 


\section{Introdução}

Cada vez mais, a criatividade do professor é elemento fundamental no processo educativo devido à necessidade de atualização da escola e à demanda de uma sociedade em permanente transformação. As pesquisas têm enfatizado a importância da criatividade docente para que o estudante possa aprender e desenvolver-se criativamente (Davis, Kogan e Soliman, 1999; Fleith, 2000; Mitjáns Martínez, 2000; Sternberg e Williams, 1996; Wechesler, 1995; Woods, 1995). No entanto, o tema da criatividade do professor é relativamente pouco estudado como notam Mitjáns Martínez (2000), Santos (1995) e Woods (1995).

Nosso interesse foi ajudar a preencher essa lacuna, investigando a constituição subjetiva da criatividade docente em contexto real. Inicialmente, podemos definir nosso foco de pesquisa como a relação entre o sentido da criatividade para o professor e sua prática pedagógica.

$\mathrm{Na}$ Psicologia da Criatividade, a percepção do professor acerca da própria criatividade é objeto de estudos de suma importância. Esta linha mostra que o autoconceito e o conceito de criatividade do professor influenciam as possibilidades de ele manifestar ou desenvolver sua criatividade (Alencar, 1992; Alencar e Fleith, 2003; Alencar, Fleith e Virgolim, 1995; Fresquet, 2000). Alencar, Fleith e Virgolim (1995) assumem que a auto-imagem tende a se refletir na ação. Quanto às vivências emocionais do professor, Woods (1995) reconhece que a sensação de auto-realização relaciona-se à manifestação da criatividade. Alencar, Fleith e Virgolim (1995) e Mariani (200I) encontram relação entre o medo do erro, da crítica e do ridículo e a inibição do comportamento criativo.

No que concerne ao estudo sobre a prática docente, encontramos produção escassa. Com raras exceções (Woods, 1995 e Martinelli, 2000), a criatividade do professor tem sido investigada de forma descontextualizada, assim como as iniciativas para o seu desenvolvimento (Anaruma, 1992 e Alencar, 1992) não têm se estruturado com base na prática cotidiana. Ao que parece, isso se deve a uma concepção implícita da criatividade como processo intrapsíquico (Mitjáns Martínez, 1997). A esse respeito, Alencar (1992: 82), que utilizou testes da Bateria Torrence de Pensamento Criativo num estudo interventivo, reconhece ser necessário "o uso de outras medidas que não testes de criatividade". Notase uma conscientização da necessidade de compreender a criatividade em sua expressão contextualizada, muito embora tais pesquisas ainda não sejam a regra.

$\mathrm{Na}$ literatura, a prática com projetos figura como uma estratégia criativa de ensino (Woods, 1995) e favorecedora da criatividade (Sternberg e Williams, 1996) e explica por que a escolhemos como foco de análise. Trata-se de uma prática produtiva, em que a aprendizagem dos conteúdos se dá através de projetos de trabalho (Hernández, 1998; Kleiman e Moraes, 1999; Nogueira, 2003; Zabala, 1998).

Optamos por uma abordagem teórica de caráter complexo e dinâmico da relação entre sentido e ação, evitando a visão de um relacionamento meramente linear. Trata-se da teoria histórico-cultural da subjetividade desenvolvida por González Rey (1997, 1999, 200I, 2002b, 2004) que permite compreender a criatividade como processo da subjetividade constituída nas interações do sujeito em contexto social (Mitjáns Martínez, 1997, 2004).

Entendemos o sentido subjetivo como "a unidade constituinte da subjetividade que integra aspectos simbólicos, significados e emoções" (González Rey, 2002b: II3). O sentido subjetivo da criatividade se relaciona à personalidade como um todo. Trata-se não de uma entidade isolada e estática mas de uma unidade sistêmica e processual constituída permanentemente da atuação do sujeito nos espaços sociais em que convive. Assim, pesquisas das percepções do professor sobre a criatividade, embora abordem representações cognitivas e até emoções que participam do sentido subjetivo, não contemplam a unidade cognitivo-afetiva dinâmica implicada nessa categoria teórica. Com a presente pesquisa pretendemos, portanto, não apenas identificar a relação, mas compreender melhor sua dinâmica.

Além do sentido subjetivo da criatividade, utilizamos a categoria teórica de sistema de atividadescomunicação, esta última na abordagem da prática 
com projetos. $\mathrm{O}$ sistema de atividades-comunicação é pautado nas características dos processos de comunicação e atividade desenvolvidos a partir de determinada prática social em certo contexto social (González Rey, 1995; Mitjáns Martínez, 1997).

A partir dessa visão teórica geral, explica-se melhor - objetivo central da pesquisa que ora relatamos: compreender a relação entre o sentido subjetivo da criatividade do professor e sua prática pedagógica com projetos. Trata-se da relação entre a forma como o professor lida subjetivamente com a criatividade, em termos das emoções e significados que gera para esse processo, e a forma como desenvolve sua prática com projetos.

\section{Método}

Tendo em vista a complexidade de nosso objeto de estudo, optamos pelo estudo de caso, que "constitui um processo irregular e diferenciado que se ramifica à medida que o objeto se expressa em toda a sua riqueza" (González Rey, 2002a: 7I). Da mesma forma Menga Ludke (1986: 2I) indica esse método de pesquisa quando se pretende explorar a complexidade manifesta na singularidade: "o objeto estudado é tratado como único, uma representação singular da realidade que é multidimensional e historicamente situada".

\section{Os Participantes e a Escola}

Os casos de dois professores, que trabalham atualmente com a pedagogia de projetos em uma mesma escola, foram estudados. Roberta', 44 anos, é professora de História das $7^{\mathrm{a}}$ e $8^{\mathrm{a}}$ séries na escola de nossa pesquisa e leciona também na rede pública de ensino. Quanto a Augusto, 31 anos, é professor de Geografia do Ensino Médio na escola de nossa pesquisa, leciona em outra escola particular e em uma faculdade.

A escola em questão, embora em um momento de transformações (maior incentivo à prática pedagógica com projetos, por exemplo), caracterizase como tradicional em função de diversos aspectos: a supervalorização da avaliação quantitativa, os conteúdos conceituais disciplinares como centro do processo de ensino-aprendizagem, o livro didático e o quadro negro como principais recursos didáticos etc.

\section{Instrumentos}

Utilizamos uma multiplicidade de instrumentos e preferimos instrumentos abertos e semi-abertos em que a expressão livre do sujeito fosse favorecida.

Realizamos quatro entrevistas, uma aberta inicial e três semi-estruturadas. A entrevista inicial tratou de aspectos gerais significativos da vida do participante. A primeira entrevista semi-estruturada tematizou a prática profissional; a segunda, a criatividade; e a última foi personalizada para cada participante, visando a obter informações que nos permitiram esclarecer as hipóteses que, como pesquisadores, vínhamos construindo sobre nosso objeto de estudo.

Utilizamos também a técnica de completamento de frases, idealizada por Rotter (1950, citado por Anastasi e Urbina, 2004) e adaptado por González Rey e Mitjáns Martínez (1989), com o objetivo de diagnóstico da personalidade. $\mathrm{O}$ instrumento consistiu em 73 frases incompletas. Outro instrumento utilizado foi redação. Os professores escreveram duas redações, a primeira tendo por tema 'O sentido da minha vida' e a segunda, 'Minha profissão'. Houve também análise documental de projetos escritos, dos diferentes instrumentos de avaliação elaborados pelos professores, da produção dos alunos na prática com projetos e documentos admnistrativos da escola relativos a atividades de saída de estudos.

Realizamos nesta pesquisa $\circ$ tipo de observação estruturada (Alves-Mazzotti e Gewandsznajder, 2002), a partir de um roteiro adaptado do roteiro de observação proposto por Mitjáns Martínez (inédito). Observamos aulas, saídas de estudo e reuniões pedagógicas.

Além dos instrumentos previstos, nos dois casos houve situações e atividades informais que geraram

Os nomes utilizados são fictícios, conforme ditam os critérios éticos da pesquisa. 
relevantes, informações como a observação do momento de intervalo dos professores, conversas informais com os participantes, com outros professores, com o diretor e a coordenadora pedagógica com os alunos, entre outras.

\section{Procedimento}

A pesquisa consistiu em uma situação comunicativa em que se buscou o estabelecimento, a manutenção e o aprofundamento de um diálogo contínuo entre pesquisador e pesquisado. Por isso, o principal instrumento foi entrevista, na concepção de entrevista como processo (González Rey, 1997). Foi importante o revezamento entre as entrevistas e os instrumentos escritos, pois um tipo funciona como descentralizador da dinâmica de relação promovida pelo outro e viceversa (González Rey, 2002b). Quanto à observação, caracterizou-se como não-participante nas aulas e reuniões pedagógicas e como participante nas saídas.

O local e horário da aplicação dos instrumentos foi aquele mais conveniente para os professores. As entrevistas e as aulas foram gravadas em fita microcassete.

\section{Análise da Informação}

A análise da informação consistiu em um processo construtivo-interpretativo por parte do pesquisador, fundamentado na epistemologia qualitativa proposta por González Rey (1997, 200I). O essencial, neste tipo de análise, é a produção de indicadores, em função da informação obtida através dos instrumentos utilizados. A informação obtida em cada um deles é articulada com aquela procedente dos outros instrumentos, a partir dos indicadores que emergem como relevantes. $O$ indicador se estabelece a partir de uma ou várias informações, num processo em que “o curso da produção de informação é, simultaneamente, um processo de produção de idéias" (González Rey 2002a: 97). Nesse processo, dois critérios foram importantes na definição da relevância da informação: o vínculo afetivo com o conteúdo expressado e a elaboração personalizada da informação por parte dos sujeitos pesquisados (González Rey e Mitjáns Martínez, 1989). A geração de indicadores é, portanto, um processo de construção que integra diferentes informações a partir do pensamento do pesquisador direcionado pelos critérios de interpretação da informação mencionados pela problemática da pesquisa e pelo marco teórico adotado.

\section{Resultados}

$\mathrm{Na}$ apresentação dos resultados, procuramos descrever de modo sintético o sentido subjetivo da criatividade e o sistema de atividades-comunicação predominante na prática com projetos dos professores. Nossos resultados mostraram a relação estudada, trazendo, às vezes, informações aportadas por diferentes instrumentos apenas como um recurso ilustrativo do processo de construção e análise da informação realizada.

\section{O Caso de Roberta}

O sentido subjetivo da criatividade é gerado por Roberta em sua prática e está integrado por dois elementos de sentido centrais. Um deles refere-se ao estado dinâmico da necessidade de criar, animado pelo entusiasmo diante do processo criativo e pela sensação de realização de si e relacionado à significação da criatividade como um processo interativo em que a interação é vista como integrante e motivadora. $O$ outro liga-se a um conflito emocional em que a ansiedade e o medo do fracasso vêm contrapostos à necessidade de criar, o que se relaciona a uma significação da criatividade marcada pelo senso comum, algo raro e restrito ao domínio das artes.

Os aspectos do sistema de atividades mais relevantes de sua prática com projetos são a pesquisa como principal atividade dos projetos e produção artística e artesanal como principal forma de atividade produtiva, a relativa heterogeneidade das atividades, principalmente na fase de produção dos alunos, a predominância de atividades extraclasse, a atividade de estudo do professor como parte da prática pedagógica e relativização do livro-texto como principal recurso didático. $O$ sistema de comunicação tem se estruturado principalmente com pouca negociação com os alunos a respeito do eixo temático 
do projeto, usando-se a produção dos alunos como objeto de comunicação entre alunos e professor e baseando-se na informalidade e precariedade da comunicação com outros professores sobre o trabalho com projetos realizados.A relação que se estabelece entre o sentido subjetivo da criatividade de Roberta e sua prática pedagógica com projetos é recursiva. Essa recursividade pode ser percebida, em dois momentos, quando da regulação da ação pedagógica.

\section{Regulação da ação pedagógica a partir do sentido subjetivo da criatividade}

O sentido subjetivo da criatividade participa centralmente a partir da regulação das ações da professora na própria busca pela pedagogia de projetos na prática inovadora. A valorização da produção dos alunos, tanto na comunicação como por meio da heterogeneidade de produtos (aspecto que, por sinal, não ocorre em projetos desenvolvidos por outros professores da escola) é impulsionada por sua necessidade de criar relacionada à significação de interatividade do processo criativo. Roberta quer promover a participação ativa dos alunos, pois além de representar o fruto de seu trabalho, é vista como motivadora da própria criatividade, conforme se nota na entrevista aberta: "se você parar, você não consegue acompanhar toda essa inquietude da juventude, da adolescência (...). Então se você tem essa disponibilidade de estar criando, o aluno também cria".

Há também a ansiedade e o medo do fracasso integrados no sentido subjetivo da criatividade de modo contraditório à necessidade de criar. Para minimizar a ansiedade que vivencia nos momentos do desenvolvimento do projeto em que não terá grande controle sobre o que os alunos realizam, Roberta acaba evitando a utilização do espaço de sala de aula bem como a negociação do eixo central dos projetos; este momento acaba comprometendo a qualidade na comunicação entre os professores. Assim, é importante lembrar que a produção de sentidos é um processo contextualizado e o sentido tradicional de ensino predominante na escola participa na geração dessas emoções conflitivas:
“... quando eu fico preocupada é na hora da avaliação as pessoas não entenderem o que que está sendo proposto. É a minha grande preocupação. (...) $O$ erro pra mim, eu tenho medo do erro. Sinceramente, porque... Mas eu me cerco. Eu me cerco." (entrevista semi-estruturada III)

A ansiedade e o medo do fracasso, de forma menos óbvia, também estão na base da busca por estudos que justifiquem e orientem suas iniciativas, e da promoção da pesquisa, na maioria das vezes de caráter reprodutivo, como principal atividade dos projetos. Um momento de sua expressão revela a participação desse conflito emocional na assunção do estudo como parte integrante de sua prática:

"O mais difícil é também buscar o entendimento de que - se bem que já mudou muita coisa - buscar o entendimento de que pode ser uma das práticas pedagógicas muito relevantes. Buscar mais, estudar. Fazer grupos de estudo sobre isso." (entrevista semi-estruturada I)

\section{Subjetivação da prática com projetos no sentido subjetivo da criatividade}

A novidade, a produção ativa e a interatividade da pedagogia de projetos têm suscitado em Roberta o entusiasmo e a sensação de realização de si, emoções motivadoras da necessidade de criar. Em entrevista, ela expressa: "O que eu preciso ainda pra fazer o meu aluno... pelo menos chegar $60 \%$ da turma estar interessado, motivado? Em pedagogia de projetos eu vejo 70 , já vi $80 \%$ interessado." (entrevista semiestruturada I) E no completamento de frases: "Minhas melhores atitudes quando estou envolvida num projeto e que os meus alunos demonstram a sua criatividade."

Além disso, notamos que alguns aspectos da prática que implicam momentos de tensão e conflito da professora têm o potencial de contribuir para uma transformação qualitativa do sentido subjetivo da criatividade: a pesquisa, se vivida cada vez mais como atividade produtiva e problematizadora do conhecimento, o estudo da professora concomitante à prática e, talvez principalmente, uma comunicação 
de maior qualidade entre os professores. Sobre um dos poucos projetos (os mais recentes) em que a pesquisa se caracterizou como uma atividade produtiva, a professora demonstra seu entusiasmo: "Como esse povo se divertia num lugar que só tinha poeira? Teve gente que perguntou. Então cria elementos pra que $\circ$ aluno tenha uma motivação pra fazer. (...) Livro nenhum de história vem isso." (entrevista semi-estruturada I)

\section{O Caso de Augusto}

Identificamos três elementos centrais quanto à forma, na configuração do sentido subjetivo da criatividade de Augusto. $O$ primeira relaciona-se ao estado dinâmico de necessidade de criar, que se integra à excitação diante do risco e do desafio e se relaciona com a significação da criatividade como espaço de definição de sua identidade e processo intuitivo, ligado à experimentação e ao improviso. O segundo, a percepção do processo criativo como processo contextualizado em que a influência social tem lugar com uma sensação de auto-realização e orgulho por si. O terceiro implica numa visão da criatividade como fonte de poder social implicando uma emoção conflitante em relação ao sentido subjetivo do outro social: desconfiança e descrédito.

As principais características do sistema de atividades da prática com projetos de Augusto foram a predominância da atividade de saída de campo, a homogeneidade na produção final dos alunos, a cooperação nas saídas de campo, o espaço natural como espaço de aprendizagem e utilização informal do espaço de sala de aula para os objetivos do projeto e a superação do livro didático como principal fonte de informação em favor das experiências de campo.

O sistema de comunicação se caracteriza principalmente pela falta de negociação quanto ao eixo central do projeto, pelas experiências de campo como principal objeto de comunicação e pela informalidade no exercício da liderança entre os professores.

No caso de Augusto há também evidências quanto à recursividade da relação entre sua prática com projetos e o sentido subjetivo da criatividade. Faz-se a analise baseada nessas premissas.

\section{Regulação da ação pedagógica a partir do sentido subjetivo da criatividade}

Sua necessidade de criar está na base dos vários aspectos de sua prática com projetos. Augusto acredita, por exemplo, que a cooperação nas saídas proporciona segurança para que o grupo possa lidar com a dose de experimentação que ele faz questão de imprimir aos trajetos. Busca as experiências de campo como objeto de comunicação, a informalidade na comunicação com os professores e a utilização informal do espaço de sala de aula como forma de viver sua criatividade de maneira espontânea, construindo uma identidade profissional diferenciada. É o que indica sua expressão:

"Quando você senta em um grupo de alunos, passa alguns minutos já estão falando nas saídas e aí é onde você começa a ensinar pros caras (...) $E$ é isso que é importante, isso está gerando experiência na vida deles, de muitos ali. E é onde você vê o projeto acontecer, ou os objetivos ou os resultados." (entrevista semi-estruturada III)

"Tenho a sensação que estou à espera de algo, e por isso preciso estar me movimentando: ser dinâmico. Ser dinâmico, profissionalmente falando, é inovar. Fazer coisas diferentes (de uma outra forma)." (redação I)

Ao lado disso, o elemento de sentido conflitivo relacionado à significação da criatividade como fonte de poder tem contribuído para a falta de negociação quanto ao eixo central do projeto e para a homogeneidade na produção final dos alunos. Augusto evita discutir o cerne dos projetos com seus pares, com a coordenação pedagógica ou com os alunos, pois receia ou a incompreensão de quem não reconhece o caráter prático dos projetos como sua principal característica ou a inveja de quem o vê como modelo: "Meu principal problema não ser entendido em alguns momentos; Não posso ter medo (demonstrar); Me incomodam os falsos (pessoas)" (completamento de frases) É o que também se nota na entrevista sobre criatividade: "Então essa história da criatividade também... (...) As pessoas que não são tão criativas começam a ser pressionadas porque 
alguém começa a te utilizar como modelo. E não é todo mundo que gosta disso não."

\section{A subjetivação da prática com projetos no sentido subjetivo da criatividade}

A vivência da prática com projetos por Augusto tem sido importante relacionada à geração de seu estado dinâmico da necessidade de criar. Trata-se da sensação de realização de si que ele experimenta em suas ações voltadas para a integração da comunidade escolar em torno dos projetos, e da excitação relativa ao risco e ao desafio experimentada nas atividades de campo e também em suas tentativas de contextualizar e personalizar o discurso docente aproveitando de modo informal o espaço de sala de aula. Um momento de sua expressão que indica a geração dessas emoções motivadoras: "Pelo menos as pessoas me passam o retorno de que: olha, eu cresci. No momento que eu abro, me abro, eu estou possibilitando as pessoas a se abrirem." (entrevista aberta)

A prática com projetos tem se constituído como um espaço potencial de desenvolvimento do sentido subjetivo da criatividade para Augusto. O clima de ajuda mútua das saídas bem como a maior centralidade da comunicação dos professores em comparação com a prática tradicional permitem que ele reveja sua forma de relacionar-se com o poder, amenizando a desconfiança e o descrédito em relação ao outro. Em entrevista:

"No momento em que você começa a entender o projeto como algo maior, além dos seus interesses, você começa a transportar isso pro interesse coletivo (...) trabalhar com os outros acaba sendo tão gratificante quanto... mais gratificante do que trabalhar sozinho." (entrevista semi-estruturada I)

\section{Discussão}

Buscando compreender a relação entre o sentido subjetivo da criatividade do professor e sua prática com projetos, nossa pesquisa nos conduziu a três conclusões gerais relacionadas ao sentido subjetivo da criatividade do professor e sua prática pedagógica

\section{A relação entre o sentido subjetivo da criatividade do professor e sua prática pedagógica com projetos é recursiva.}

Ao se referir à relação entre sentido subjetivo e ação, González Rey (1997, 2002b, 2004) aponta para uma implicação e transformação mútua, sempre renovada na vida do sujeito e no curso processual de sua ação. Nossa pesquisa vem corroborar esta concepção no que concerne à criatividade do professor, reconhecendo a recursividade da relação estudada. $O$ sentido subjetivo da criatividade participa fortemente na regulação das ações do professor em sua prática com projetos e essa prática repercute no sentido da criatividade, contribuindo para sua geração e possível transformação.

Há, portanto, uma relação de regulação e não de determinação linear do sentido sobre a ação. Por exemplo, a significação da criatividade como processo interativo não implica irrestritamente a promoção dessa característica, como notamos no caso de Roberta. A professora chega a incentivar a heterogeneidade na produção dos alunos, mas, devido à ansiedade vivida no processo criativo, acaba evitando a negociação nos projetos que desenvolve. Percebeuse a fluidez do sentido subjetivo da criatividade, que varia seus elementos integrantes no curso processual da ação como notou Mitjáns Martínez (2004).

As ações implementadas no interior da prática com projetos ajudam na geração do sentido subjetivo da criatividade. Nesse processo, é importante que a subjetivação das próprias ações gere emoções que animem a necessidade de criar do professor, como o entusiasmo diante do processo criativo, a excitação diante do desafio, a satisfação e sensação de auto-realização, esta última também destacada por Woods ( 1995) como participante na criatividade do professor. É o caso da sensação de realização de si que Augusto experimenta na vivência da avaliação processual de seus projetos.

Embora concordemos sobre a importância do papel da dimensão subjetiva nas manifestações criativas do professor (Alencar, 1992; Alencar, Fleith e Virgolim, 1995; Fresquet, 2000; Mariani, 200I), as noções de reflexo, correspondência ou mera influência são discutíveis. O reconhecimento do papel central da subjetivação da ação na geração de sentido para a 
criatividade nos faz questionar a mera influência das percepções e emoções do professor sobre a ação criativa sem o reconhecimento da recursividade dessa relação.

\section{A relação recursiva entre o sentido subjetivo da criatividade do professor e sua prática pedagógica com projetos é mediada pelo sentido subjetivo de elementos contextuais de sua prática.}

Esta pesquisa evidenciou, principalmente, a mediação do sentido subjetivo do outro social e do sentido subjetivo do espaço de sala de aula e confirmou que na geração da necessidade de criar, o outro social participa como sentido subjetivo enquanto "grupo a ser ultrapassado ou transcendido, como alguém do qual diferenciar-se, como alguém perante o qual se deve mostrar competência e orginalidade" (Mitjáns Martínez, 2004: 89), principalmente no caso de Augusto. Também reconhecemos a participação do sentido do outro como alguém a quem se serve e como parceiro criativo no sentido da criatividade, especialmente no caso de Roberta.

A partir dos dois casos, notamos ainda que o sentido do outro como avaliador externo, e como alguém a quem controlar pode gerar emoções contraditórias à necessidade de criar quanto à desconfiança, ao descrédito ou ansiedade e ao medo do fracasso. Assim, é importante lembrar que o professor se insere em uma prática predominantemente individualista. Nesse sentido, a prática com projetos tem a possibilidade de trazer alguns elementos novos de experiência em relação à forma e como o professor gera o sentido subjetivo do outro social. As relações familiares, as relações de amizade na escola e em outros contextos e as relações de coleguismo, nenhuma delas é estruturada como aquelas entre professores no âmbito de um projeto de trabalho. A interação com seus pares é centralizada, o momento de significação da ação do professor e da relação com os alunos torna-se mais horizontal. Assim, a possibilidade de que o sentido subjetivo do outro social evolua a prática com projetos parece depender das características do sistema de atividadescomunicação como a negociação, a centralidade da comunicação entre os professores, a heterogeneidade na produção e a predominância de atividades cooperativas. Já o sentido subjetivo de sala de aula, relacionado ao modelo de educação reprodutivo e autoritário, é integrado por uma forte conotação de poder ligada à concepção reprodutiva do processo de ensino-aprendizagem. Este elemento pode estar presente no sentido da criatividade, contribuindo para que o professor evite o espaço de sala de aula para as atividades de projetos, como no caso de Roberta.

Simultaneamente e em contrapartida, a vivência da prática pedagógica em espaços diferentes tem se configurado como uma situação potencial de desenvolvimento para os sujeitos. São situações que envolvem um outro clima emocional, de maior informalidade e cooperação, bem como envolvem a utilização de fontes variadas de informação. No caso de Augusto, notou-se como a experiência de outros espaços de aprendizagem contribui inclusive para uma vivência diferenciada do próprio espaço de sala de aula.

\section{Aspectos conflitivos do sentido subjetivo da criatividade tendem a se expressar em contradições ou conflitos na prática com projetos do professor e vice-versa, situação que pode ser de desenvolvimento para o sujeito.}

González Rey (1997: I 24-I25) afirma que "qualquer conflito em termos interativos simultaneamente estará constituído em nível da personalidade, níveis diferentes que se integram no complexo processo de desenvolvimento do conflito". Os conflitos interpessoais entre os professores e as contradições que se verificam na estruturação da prática pedagógica muitas vezes expressam contradições vividas no sentido subjetivo da criatividade. Foi o que notamos, por exemplo, em relação à desarticulação entre as atividades de pesquisa, predominantemente reprodutivas, e as atividades de produção artística nos projetos de Roberta, em que a ansiedade e o medo do erro a impediam de ou conceber a pesquisa como uma atividade não meramente reprodutiva mas de construção do conhecimento ou estabelecer as atividades de produção artística como eixo dos projetos, articulando melhor as duas atividades. 
Numa concepção dialética da subjetividade, González Rey (1997, 2002b) reconhece a contradição e a oposição como momentos necessários ao desenvolvimento. Outros autores também têm compreendido o elemento conflitivo como aspecto necessário ao desenvolvimento (Valsiner e Cairns, 1992; Vygotsky, 1990).

Dessa forma, a relação entre o sentido subjetivo da criatividade do professor e sua prática com projetos implica uma possível situação de desenvolvimento para o sujeito em dependência da evolução dos aspectos conflitivos que se expressam nos dois pólos. Nos casos estudados, o desenvolvimento qualitativo do sentido da criatividade dependeria da evolução dos aspectos contraditórios configurados, em relação à ansiedade e medo do fracasso, no caso de Roberta, e em relação à desconfiança e descrédito, no caso de Augusto.

\section{Considerações Finais}

A participação do sentido subjetivo da criatividade na regulação das ações do professor, por um lado, confirma a importância, ressaltada por Mitjáns Martínez (1997, 2000, 2004), de avançarmos na compreensão da forma em que a criatividade se constitui subjetivamente. Por outro lado, o papel da prática com projetos no sentido subjetivo da criatividade desafia a noção da ação como o momento de manifestação de um nível de criatividade que o sujeito já apresentaria a priori, visão muito relacionada à ênfase nos aspectos intrapsíquicos relacionados à criatividade. Nesse sentido, esta pesquisa demonstrou como se reconstroem elementos de sentido na ação a partir das emoções que a ação suscita. Por isso, confirmamos a necessidade de se estudar a criatividade de forma contextualizada nos espaços vivos.

Além disso, ressaltamos a possibilidade de a escola se valer da prática com projetos como um sistema de atividades-comunicação favorecedor do desenvolvimento da criatividade do professor. Assim, - caráter subjetivo desse desenvolvimento deixa patente a necessidade de intervenção do psicólogo escolar, atuando mais próximo ao professor.

\section{Referências}

Alencar, E. M. S. (1992). Pensando no futuro: a necessidade de se promover a criatividade no contexto educacional. Em Z. G. Giglio (Org.), De criatividade e de educação. (pp.65-89) Campinas,SP: Núcleo de estudos psicológicos-UniCamp.

Alencar, E. M. L. S. \& Fleith, D. S. (2003). Barreiras à criatividade pessoal entre professores de distintos níveis de ensino. Psicologia Reflexão e Crítica, 16, 63-69.

Alencar, E. M. L. S., Fleith, D. S. \& Virgolim, A. M. R. (1995). Fatores inibidores à criatividade em estudantes universitários e professores. Anais, XVII Congresso Internacional de Psicologia Escolar, tomo II, 105-109.

Alves-Mazzotti; A. J. ,\& Gewandsznajder, F. (2002). O método nas ciências naturais e sociais: pesquisa quantitativa e qualitativa. 2 ed. São Paulo: Thompson.

Anaruma, S. M. (1992). Vivências em criatividade para professores: relato de uma experiência. Em Z. G. Giglio (Org.), De criatividade e de educação. (pp.|139-170) Campinas,SP: Núcleo de estudos psicológicos - Unicamp.

Anastasi, E. \& Urbina S. (2004). Testagem psicológica. $7^{\mathrm{a}}$ ed. Porto Alegre,RS: ArtMed.

Bezerra, C. S. G. B. (2004). O sentido subjetivo do aprender. Dissertação de Mestrado,

Universidade Católica de Goiás, Goiânia - GO.

Coelho, C. M. M. (2004). Um olhar sobre a relação sujeitolinguagem: a subjetividade e os transtornos da comunicação. Tese de doutorado, Universidade de Brasília, Brasília - DF.

Davis G. A., Kogan N. \& Soliman A. M. (1999). The Qatar Creativity Conference: Research and recommendations for school, family, and society. The Journal of Creative Behavior, 33, 151-166.

Fleith, D. S. (1994). Treinamento e estimulação da criatividade no contexto educacional. Em E. M. L. S. Alencar \& A. M. R. Virgolim (Orgs.) Criatividade: Expressão e Desenvolvimento. Petrópolis,RJ: Vozes.

Fleith, D. S. (2000). Teacher's and student's perceptions of creativity in the classroom environment. Roeper Review Bloomfield Hills, Michigan, 22, I48-I53.

Fresquet A. M. (2000). Processo de co-construção do conceito de criatividade por professores de Educação Infantil: uma análise microgenética. Dissertação de Mestrado, Universidade de Brasília, Brasília- DF. 
González Rey, F. L. (1995). Comunicación, personalidad y desarrollo. Habana: Pueblo y Educación.

González Rey, F. L. (1997). Epistemologia cualitativa y subjetividad. Habana: Pueblo y Educación.

González Rey, F. L. ( 1999). La afectividad desde una perspectiva de la subjetividad. Psicologia: Teoria e Pesquisa, 15, I27134.

González Rey, F.L. (200I). La categoría de sentido subjetivo y su significación en la construcción del pensamento psicológico. Contrapontos: Psicologia histórico-cultural, I (2), 13-28.

González Rey, F. L. (2002a). Pesquisa qualitativa em psicologia: caminhos e desafios. São Paulo,SP: Ed. Thomson.

González Rey, F. L. (2002b). Sujeto y subjetividad: una aproximación histórico-cultural. México: Ed. Thomson.

González Rey, F. L. (2004). O social na psicologia e a psicologia social: a emergência do sujeito. Petrópolis, RJ: Ed. Vozes.

González Rey, F. L. \& Mitjáns Martínez, A. (1989). Personalidad: Su educacion y desarrollo. Habana: Pueblo Y Educación.

Hernández, F. (1998). Transgressão e mudança na educação: Os projetos de trabalho. Porto Alegre,RS: ArtMed.

Kleiman, A. B. \& Moraes S. E. (1999). Leitura e interdisciplinaridade: tecendo redes nos projetos da escola. Campinas,SP: Mercado de Letras.

Menga Ludke, M. E. d. A. A. (1986). Pesquisa em educação: abordagens qualitativas. São Paulo,SP: EPU.

Mariani, M. de F. M. (200I). Criatividade e trabalho pedagógico: limites e possibilidades

na expressão da criatividade do professor de História. Dissertação de mestrado. Universidade Católica de Brasília, Brasília- DF.

Martinelli S. S. (2000). No ensino, quem dança? Dissertação de Mestrado, Universidade de Brasília, Brasília- DF.

Mitjáns Martínez, A. (1997). Criatividade, Personalidade e educação. Campinas,SP: Papirus Editora.
Mitjáns Martínez, A. (2000). Pensar, crear y transformar: Desafíos para la educación. Anais, I Simpósio Multidiscplinar: Pensar, Criar, Transformar, 15-25.

Mitjáns Martínez, A. (2004). O outro e sua significação para a criatividade: Implicações educacionais. Em L. M. Simão \& A. Mitjáns Martínez (Orgs.), O outro no desenvolvimento humano: diálogos para a pesquisa e a prática profissional em psicologia (pp. 77-99). São Paulo,SP: Ed. Thomson.

Nogueira; N. R. (2003). Pedagogia dos projetos: uma jornada interdisciplinar rumo ao desenvolvimento das múltiplas inteligências. São Paulo,SP: Ed. Érica.

Santos, A. T. (1995). Estudo da criatividade no Brasil: Análise das teses/dissertações em Psicologia e Educação (1970/1993). Dissertação de Mestrado, Universidade Estadual de Campinas, Campinas- SP.

Sternberg, R. J. \& Williams, W. M. (1996). How to develop student's creativity. Alexandria, VA: Association for Supervision and Curriculum Development.

Valsiner, J. \& Cairns, R. (1992). Theoretical perspectives on conflict and development. Em: C.V. Shantz \&W.W. Hartup (Orgs.) Conflict in child and adolescent development (pp. 15-35). Cambridge, MA: Cambridge University Press.

Vygotsky L. S. (1990). Imagination and creativity in childhood. Soviet Psychology, 28, 84-96.

Wechsler, S. M. (1995). O desenvolvimento da criatividade na escola: Possibilidades e implicações. Estudos de Psicologia, 12, 81-86.

Woods, P. (1995). Aspectos sociais da criatividade do professor. Em Nóvoa, A. (Org.) Profissão professor (pp. 125-153). Portugal: Porto Editora.

Zabala, A. (1998). A prática educativa: como ensinar. Porto Alegre,RS: ArtMed.

Recebido em: 21/02/2006

Revisado em: 10/08/2006

Aprovado em: 03/10/2006

Sobre as autoras

Renata Fernandes Mourão (renata.fernandes.m@gmail.com.br)é mestre pela Universidade de Brasília.

Albertina Mitjáns Martínez (amitjans@terra.com) é doutora e docente da Universidade de Brasília.

Endereço para correspondência

Albertina Mitjáns Martínez

SQS 407, bloco R, apto. 206

70256 - 190 - Brasilia, DF 